\title{
Diversity of heterotrimeric G-protein $\gamma$ subunits in plants
}

Yuri Trusov ${ }^{1}$, David Chakravorty ${ }^{2}$ and José Ramón Botella ${ }^{1 *}$

\begin{abstract}
Background: Heterotrimeric G-proteins, consisting of three subunits $G a, G \beta$ and $G \gamma$ are present in most eukaryotes and mediate signaling in numerous biological processes. In plants, $G$ y subunits were shown to provide functional selectivity to G-proteins. Three unconventional Gy subunits were recently reported in Arabidopsis, rice and soybean but no structural analysis has been reported so far. Their relationship with conventional Gy subunits and taxonomical distribution has not been yet demonstrated.

Results: After an extensive similarity search through plant genomes, transcriptomes and proteomes we assembled over 200 non-redundant proteins related to the known Gy subunits. Structural analysis of these sequences revealed that most of them lack the obligatory C-terminal prenylation motif (CaaX). According to their C-terminal structures we classified the plant $G$ y subunits into three distinct types. Type A consists of $G y$ subunits with a putative prenylation motif. Type B subunits lack a prenylation motif and do not have any cysteine residues in the C-terminal region, while type $\mathrm{C}$ subunits contain an extended C-terminal domain highly enriched with cysteines. Comparative analysis of C-terminal domains of the proteins, intron-exon arrangement of the corresponding genes and phylogenetic studies suggested a common origin of all plant Gy subunits.

Conclusion: Phylogenetic analyses suggest that types $C$ and B most probably originated independently from type A ancestors. We speculate on a potential mechanism used by those $G \gamma$ subunits lacking isoprenylation motifs to anchor the $G \beta \gamma$ dimer to the plasma membrane and propose a new flexible nomenclature for plant $G \gamma$ subunits. Finally, in the light of our new classification, we give a word of caution about the interpretation of Gy research in Arabidopsis and its generalization to other plant species.
\end{abstract}

Keywords: Heterotrimeric G-proteins, Signal transduction, Prenylation, S-acylation

\section{Background}

Heterotrimeric G-proteins, consisting of three distinct subunits: $G \alpha, G \beta$ and $G \gamma$, constitute one of the most important signal transduction systems in eukaryotes. According to the classic paradigm, ligand-bound Gprotein coupled receptors catalyze the exchange of GDP

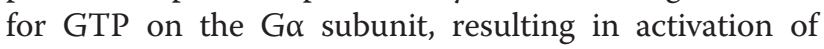
the heterotrimer and dissociation of the two functional elements, the $G \alpha$ subunit and the $G \beta \gamma$ dimer. $G \alpha$ and $\mathrm{G} \beta \gamma$ independently interact with multiple downstream effectors mediating specific signal transduction pathways until the intrinsic GTPase activity of the $\mathrm{G} \alpha$ subunit hydrolyzes GTP to GDP, which increases Go affinity for

\footnotetext{
* Correspondence: j.botella@uq.edu.au

${ }^{1}$ Plant Genetic Engineering Laboratory, School of Agriculture and Food Sciences, University of Queensland, Brisbane, Queensland 4072, Australia Full list of author information is available at the end of the article
}

the G $\beta$ y dimer, resulting in re-association of the heterotrimer at the receptor [1-3].

Plant heterotrimeric G-proteins are involved in multiple physiological processes [4-8]; however the available set of subunits is limited. In the fully sequenced Arabidopsis genome only one gene is present for the $G \alpha$ and $G \beta$ subunits [5,9], while three genes are now known for

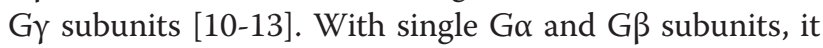
is logical to assume that $G \gamma$ is solely responsible for providing functional selectivity to the heterotrimer, as has been proven for Arabidopsis [10,14,15]. In some plants two to four canonical $G \alpha$ and $G \beta$ subunits have been identified [16-18], however their functional specificity is yet to be studied. At the same time, in one of these species, soybean, the set of Gy subunits has been expanded to 10 [19].

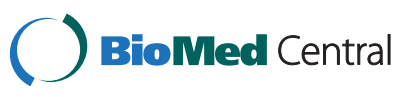


The Gy subunit is an essential part of the heterotrimer, binding tightly to $G \beta$ and anchoring the $G \beta \gamma$ dimer to the plasma membrane [1,20-23]. Most of the known $\mathrm{G} \gamma$ subunits are relatively small proteins of about $8-11 \mathrm{kDa}$ [11,12,24-26]. They contain a conserved prenylation signal at their C-termini, which is a target for posttranslational prenylation $[1,3,22,27,28]$. This modification considered to be crucial for anchoring the $G \beta \gamma$ dimer to the plasma membrane and for the entire heterotrimer function [29-32]. Recently, a novel Gy subunit has been described in Arabidopsis, AGG3, containing a large cysteine-rich $\mathrm{C}$-terminus, increasing the size of the protein to approximately $25 \mathrm{kDa}$ (251 amino acids) [10]. On the other hand, one of the reported rice $\mathrm{G} \gamma$ subunits, RGG2, does not contain a C-terminal prenylation signal [26] and similar variants were recently reported in soybean [19]. To the best of our knowledge, such severe deviations from the canonical structure have not been reported for any animal or fungal $\mathrm{G} \gamma$ subunits.

It was found that the protein structure of the $\mathrm{G} \gamma$ variants could differ dramatically within a single species $[10,19,26]$, however the extent of these proteins' diversity in plants and their phylogenetic relationships have not yet been studied. In this study we have identified over 200 non-redundant sequences of $\mathrm{G} \gamma$ subunits from seed bearing plants and analyzed their structure and phylogenetic relationships. Based on their C-terminal amino acid sequences three distinct types were revealed. A robust phylogenetic analysis suggested a common origin for the three structural types within the plant kingdom. A new flexible nomenclature for plant $G \gamma$ subunits is suggested.

\section{Results}

\section{Identification of plant $\mathrm{G} \gamma$ subunits}

Gy subunits have been characterized only in four flowering plant species: Arabidopsis [10-12], rice [26], garden pea [18] and soybean [19]. In order to identify additional $\mathrm{G} \gamma$ sequences we queried the "nucleotide collection (nr/nt)", "expressed sequence tags (est)", "high throughput genomic sequences (HTGS)" and "whole-genome shotgun reads (wgs)" databases in GeneBank using the BLAST (tblastn) algorithm [33] with the Arabidopsis and rice $G \gamma$ subunit protein sequences as queries. The published PsGy1 and PsG 2 sequences from garden pea show very low overall similarity to $G \gamma$ subunits from other species and lack the most of highly conserved residues including the DPLL motif present in all established plant and animal $\mathrm{G} \gamma$ subunits. At the same time we found one pea EST showing high similarity to Gyencoding ESTs from other plants and particularly to other leguminous species, suggesting that the published PsG 1 and PsG 2 have a different origin and therefore we did not include them in this study. In rice, in addition to the two reported Gys, RGG1 and RGG2, we have identified three other proteins sharing high similarity with the Arabidopsis $G \gamma$ subunit AGG3. Two of them, GRAIN SIZE 3 (GS3) and DENSE AND ERECT PANICLE1 (DEP1), were previously characterized but not identified as $\mathrm{G} \gamma$ subunits [34-36]. These proteins were recently reclassified as $\mathrm{G} \gamma$ subunits due to their high similarity with the experimentally proven Arabidopsis AGG3 subunit [10,37].

To exhaust the screening, newly found sequences from different plant taxa were translated into protein sequences and used as queries in additional BLAST searches. In total, over 300 non-redundant sequences representing plant $G \gamma$ subunits from land plants were obtained with more than one subunit found in most species. After discarding short and incomplete sequences, around 200 full-length or near full-length sequences were selected for analysis.

\section{Structural analysis reveals three types of plant $\mathrm{G} \gamma$ proteins}

Initial inspection of aligned putative $\mathrm{G} \gamma$ proteins revealed that the central part of the molecule was the most conserved, while $\mathrm{N}$-terminal and C-terminal regions were variable. High variability in the $\mathrm{N}$-termini has also been reported for animal Gy subunits [38], but C-terminal variability seems to be a unique characteristic of plant $\mathrm{G \gamma}$ subunits. Importantly, the variability observed in the C-termini was not random and three distinct types could be clearly identified. Based on their C-terminal amino acids, plant $G \gamma$ subunits can be divided into three structural types $\mathrm{A}, \mathrm{B}$ and $\mathrm{C}$. A schematic representation of the types is shown on Figure 1A. The central domain retains high sequence similarity in all three types indicating a close relationship and suggesting a conserved function for the domain. Multiple sequence alignments of the central domain and Cterminal region of types $\mathrm{A}$ and $\mathrm{B}$ are shown in Figure $1 \mathrm{~B}$, while only the central domain and a short fragment of the $\mathrm{C}$-terminus of type $\mathrm{C}$ is shown in the Figure. The $\mathrm{N}$-termini of the proteins were too variable to be unambiguously aligned, while the C-terminal region of type $C$ subunits was too long to be presented in the Figure.

Type A Gy subunits are small proteins (approximately 100 amino acids) containing the conserved C-terminal CaaX motif, known as a prenylation motif, which is a characteristic of all non-plant and conventional plant $\mathrm{G} \gamma$ subunits. This type is similar to all other eukaryotic $\mathrm{G} \gamma$ subunits reported so far and therefore could be considered as the archetypal heterotrimeric Gy subunits. Considering the presence of the putative prenylation motif, we have defined type A Gy subunits as short proteins with a potential site for post-translational prenylation. 


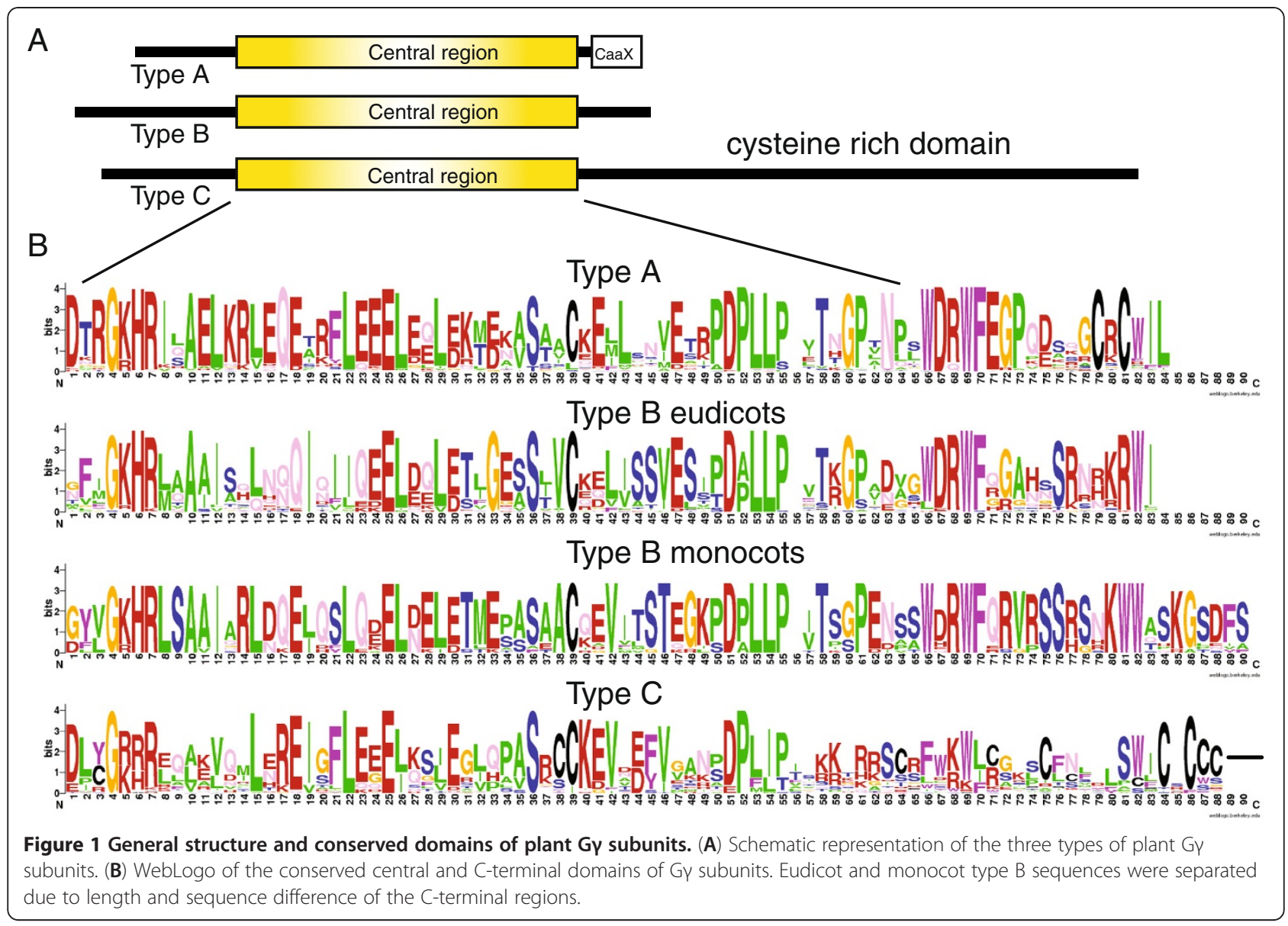

Representatives of type A were found in gymnosperms and flowering plants. Notably, in rosid species there are at least two variants of this type related to the Arabidopsis AGG1 and AGG2 proteins. At the same time most asterid species have only one Gy subunit of this type.

The second Gy subunit type, type B, has a substantial level of amino acid sequence similarity to the type $\mathrm{A} G \gamma$ subunits, however, lacks the $\mathrm{C}$-terminal $\mathrm{CaaX}$ box. Moreover, there is not a single cysteine residue in the proximity of the C-terminus. This type was found only in flowering plants, but not in gymnosperms. Surprisingly, no representatives of this type were identified in the fully sequenced Arabidopsis genome or in other intensively studied Brassicaceae genera, such as Brassica and Raphanus. Nevertheless, this gene was found in Carica papaya which belongs to the same order Brassicales, but to a different family Caricaceae, suggesting that the gene was probably lost in the Brassicaceae ancestor. The consensus C-terminus among eudicot sequences of this type is SRxxKRWI, while in monocot species the C-terminal consensus is KGSDFS (Figure 1B). Since none of these proteins contains cysteines in the $\mathrm{C}$-terminal region, we have designated this type as non-prenylated Gy subunits.
The third type, type $\mathrm{C}$, accommodates $\mathrm{G}$ y subunits with relatively large ( 70-350 amino acids) C-terminal extensions. Despite the pronounced variability in the Cterminus, sequences of this type share a considerable level of similarity with type A and B Gy subunits in the central region (Figure 1B). Importantly, they contain all, but one, of the conserved residues forming hydrogen bonds and hydrophobic contacts in the interaction between Gy and G $\beta$ (amino acids L/V12, E25, S36, D/E51, P52, L53, L/I54 in Figure 1B). These residues are also conserved in mammalian Gys [39]. Physical interaction with the $G \beta$ subunit, plasma membrane localization and genetic analysis in Arabidopsis confirmed the type $\mathrm{C}$ representative, AGG3, as a bona fide Gy subunit $[10,13]$. The C-terminal regions of type $\mathrm{C} \mathrm{Gy}$ subunits have an extremely high content of cysteine residues (19 to 38\%) and their lengths are quite variable even between closely related species (Additional file 1: Table S1). The cysteine residues are distributed randomly along the region without common recognizable domains. Repeats of 5-10 amino acids are relatively common for the cysteine rich region. For instance in cotton (Gossypium raimondii) twelve tandem repeats with sound identity can be found, suggesting recent amplification events (Additional file 1: 
Figure S1). Alignment of Arabidopsis and Brassica rapa sequences revealed at least 6 indels ranging from 3 to 51 bp (Additional file 1: Figure S2). Conifers and cycads contain the shortest cysteine-rich regions, being of similar size even among species from different families (Additional file 1: Table S1).

\section{Phylogenetic relationships within plant Gy subunits}

To investigate the generic relationships between the four identified types of plant $\mathrm{G} \gamma$ subunits we performed phylogenetic analysis. As mentioned before, the central part of the protein was the most conserved in size and amino acid sequence. The $\mathrm{N}$-termini varied in size from roughly 10 to 75 amino acids, while the $\mathrm{C}$-termini varied even more dramatically, from 20 to 350 amino acids, effectively preventing any reasonable alignment within these two regions. Therefore only the conserved central domain was used for phylogenetic analysis. The protein sequences were aligned using the CLUSTAL-OMEGA software [40] and adjusted manually. We built and compared unrooted trees using different algorithms provided in the PHYLIP 3.66 package [41] as well as maximum likelihood algorithm using the PhyLM 3.0 package $[42,43]$. The obtained trees exhibited some variation in topology and low overall statistical support (bootstrap values for PHYLIP algorithms and approximate likelihood ratio test for branches (aLRT) for PhyLM)). This was not an unexpected outcome since we used fairly short sequences. Nonetheless, most of the trees showed significant statistical support for major clusters corresponding to the proposed structural types. Therefore, although limited, very important phylogenetic information could be retrieved. Parsimony and maximum likelihood trees displayed very similar topology and provided the best fit for the currently established plant phylogeny within the sub-trees of type A, B and C [44]. For demonstration purposes we selected the parsimony tree (Figure 2) due to its higher statistical support for the designated types. The parsimonious algorithm separated type C sequences in $100 \%$ of bootstrap trees. Type B sequences were sub-clustered within type A sequences with significant (75\%) bootstrap support (Figure 2).

The phylogenetic analysis, thus, suggests that type B derived from type A sometime after flowering plants diverged from gymnosperms, but prior to the origin of monocots. This scenario corresponds well with our data mining results showing presence of type B only in flowering plants. Types $\mathrm{A}$ and $\mathrm{C}$ seem to originate before seed bearing plants diverged; in accordance, these types are present in gymnosperms and flowering plants. Several relatively recent duplication events took place within the types $A$ and $C$ resulting in the modern day diversity observed in plant $\mathrm{G} \gamma$ subunits.

\section{Gy gene structure comparison between plants and other eukaryotes}

Plant and animal $\mathrm{G} \gamma$ subunits share limited sequence similarity even at the protein level $[10,11,39]$. In order to obtain a different insight on the relationship among plant Gy subunit genes and to establish a degree of relatedness between plant and other eukaryotic $\mathrm{G} \gamma$ genes, we compared intron-exon structures of $\mathrm{G \gamma}$ genes from several species representing different eukaryotic domains (Additional file 1: Figure S3). The intron-exon structure

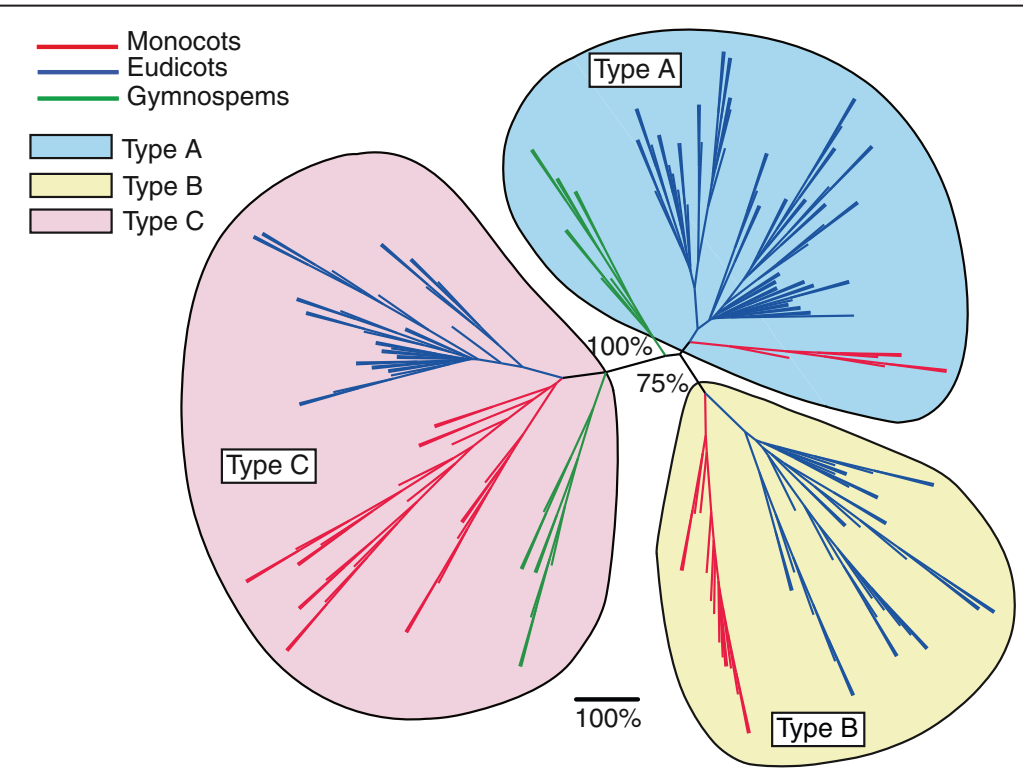

Figure 2 Phylogenetic relationships of the three types of plant Gy subunits. Consensus tree representing 1000 unrooted bootstrap trees generated by protein parsimony algorithm; percentage shows statistically significant support for clusters corresponding to the structural types. 
further supported the closer relationship between all plant $\mathrm{G} \gamma$ subunits. All tested type $\mathrm{A}$ and $\mathrm{B} \mathrm{G} \gamma$ genes have four exons and three introns within the coding region. The two middle exons were almost identical in size, reflecting the conservation of the central domain. The first and fourth exons demonstrated more variability, while the size of the three introns varied greatly. Type $C$ genes have five exons, the first four of which are similar to the exons of type A and B genes, while the additional fifth exon encodes most of the cysteine-rich tail. Projection of exon boundaries on the protein sequence displayed identical positions for all tested plant $\mathrm{G} \gamma$ genes. Noticeably, Gy genes from other eukaryotes differ from those of plants and each other in relation to intron numbers and positions. $\mathrm{G} \gamma$ genes from some fungi (Saccharomyces cerevisiae, Ashbya gossypii), the primitive eukaryote Naegleria gruberi and some metazoans such as several species of Drosophila and sea anemone Nematostella vectensis do not have introns (data not shown). On the other hand, stramenopiles (Phytophthora infestans, Ectocarpus siliculosus), fungi (Aspergillus clavatus, Laccaria bicolor), the social amoeba Dictyostelium discoideum and most animals have 1-3 introns in variable positions (Additional file 1: Figure S3). All functional human $\mathrm{G} \gamma$ genes have one intron in the same position [25]. Two human genes are presented in Additional file 1: Figure S3. At the same time several species from taxa related to vertebrates (such as Hemichordata, Cephalochordata and Echinodermata) have Gy genes with and without introns. These observations provide additional evidence supporting the close relationship within plant $\mathrm{G} \gamma$ genes, while demonstrate that exon-intron arrangements in other eukaryotic $\mathrm{G} \gamma$ genes were variable even within closely related groups. Importantly, one intron position (projected to be approximately in the middle of the protein sequence) was common for the majority of $\mathrm{G} \gamma$ genes with introns (Additional file 1: Figure S3), uniting an incredibly diverse range of eukaryotes, including plants, animals, fungi, amoebazoans and stramenopiles.

\section{C-terminus variability in eukaryotic Gy subunits}

The presence of a CaaX box and specifically the cysteine residue in the fourth position from the protein end, providing a possibility for protein prenylation, is considered a prominent feature of all known $G \gamma$ subunits [1,29,4547]. However, we found that plant $G \gamma$ subunits often lack the canonical prenylation motif. Only type A, invariably has a CaaX motif, while type B totally lacks cysteines at the $\mathrm{C}$-terminus and only approximately half of the available type $\mathrm{C}$ proteins contain a CaaX-like motif.

To study the $\mathrm{C}$-termini of $\mathrm{G} \gamma$ subunits from different eukaryotes we screened the available sequence databases using a number of established Gy sequences as a query for BLAST searches. In total $\sim 150 \mathrm{G} \gamma$ subunits from several eukaryotic groups were compared. For each eukaryotic group a consensus of $\sim 20$ C-terminal amino acids was obtained using the majority rule, when 'majority' is determined by over $50 \%$ presence; highly variable positions were substituted with ' $x$ ' (Table 1). To avoid over-representation of a single group, such as vertebrates in the consensus for animals, we first produced preliminary consensus sequences for all phyla and then joined them producing the final consensus for the kingdom. The results reflect an abundance of valine, isoleucine, methionine and leucine in the two terminal positions, while third position from the end was found to be variable in all eukaryotes, except for plants, where it is predominantly occupied by tryptophan (Table 1). Interestingly, we found that one of the most primitive single cell eukaryote, Naegleria gruberi, has two Gy subunits. One of them contains classical CaaX box, while the second protein has no prenylation motif. Unlike in plants, where non-prenylated $G \gamma$ subunits are an abundant type, Naegleria's non-prenylated variant is an isolated case. It has the highest sequence similarity with its paralog containing the CaaX motif, suggesting relatively recent divergence of the two proteins.

\section{Discussion}

The importance of heterotrimeric G-proteins in plant cell signalling is difficult to overestimate, being involved in multiple developmental processes [5,8-10,14,48-50] and innate immunity [6,7,51-56]. Most of the available studies have used Arabidopsis and rice mutants lacking either $\mathrm{G} \alpha$ or $\mathrm{G} \beta$, each encoded by a single gene in these species. In contrast, $\mathrm{G} \gamma$ is encoded by several genes in both species and their important role for the correct function of the heterotrimer has been recently demonstrated $[10,14,15,29,37]$. In this study we have analysed over $200 \mathrm{G} \gamma$ subunits from nearly 100 seed bearing plant species and found striking differences in their C-termini with many subunits lacking the 'consensus' C-terminal prenylation motif, CaaX.

\section{Table 1 C-terminal amino acids of Gy subunits from different eukaryotes}

\begin{tabular}{|c|c|}
\hline Species / Group & C-terminal amino acids \\
\hline Animals & VxxPxSENPFKEKKXGCXIL \\
\hline Fungi & VDKxEDPYAPxxxGGCCxVM \\
\hline Amoebozoa & FxGExNPWxxNQxGGCCxVI \\
\hline Stramenopiles & NDxPNxWQQSxQGGGGCXIL \\
\hline Plants type A & xWDRWFEGPQDxxGCRCWIL \\
\hline Naegleria gruberi FE249419 & SDPTNPYLNPPKDGGCCMIM \\
\hline
\end{tabular}




\section{Prenylated and non-prenylated plant Gy subunits}

It has been established in animal studies and also demonstrated in plants, that $\mathrm{G} \gamma$ anchors the G $\beta$ subunit to the plasma membrane $[1,3,10-12,21,22,27,28,32]$. This is achieved by strongly binding $\mathrm{G} \beta$ using a coiled-coil interaction and targeting the dimer to the plasma membrane via post-translational modification of the $\mathrm{G} \gamma \mathrm{C}$ terminus. Classically, post-translational processing of the Gy subunits includes prenylation and proteolytic cleavage of the last three amino acids [30-32]. Prenylation of protein C-termini in eukaryotes is catalysed by three types of protein prenyltransferases. Protein farnesyltransferase (PFT) transfers a farnesyl group to the cysteine residue of a CaaX motif, where "a" is preferably an aliphatic amino acid and " $X$ " is preferably, but not necessarily, methionine, glutamine, alanine, cysteine, or serine. Protein geranylgeranyltransferase type I (PGGT I) catalyses the transfer of a geranylgeranyl moiety to the cysteine residue of a CaaX motif, where " $\mathrm{X}$ " is preferably leucine or isoleucine. Finally, protein geranylgeranyltransferase type II (PGGT II) is highly specific for RABGTPases and requires an escort protein, therefore, it does not participate in prenylation of $\mathrm{G} \gamma$ subunits $[57,58]$. Thus, the presence of the CaaX motif is considered to be compulsory for $\mathrm{G} \gamma$ subunits.

We found that in plants only type A and about half of type $\mathrm{C} \mathrm{G} \gamma$ subunits possess a putative CaaX motif, while type $\mathrm{B}$ proteins do not have it. Even though the plant $\mathrm{CaaX}$ motif is similar to that of other eukaryotes in general terms, it has a distinct difference. In plants, the first aliphatic amino acid position of the CaaX box is frequently occupied with an aromatic amino acid tryptophan, which is otherwise never found in this position or even in the proximity of the prenylated cysteine in any other eukaryotes. This deviation from the mammalian pattern raises questions about the possible prenylation of those plant $\mathrm{G} \gamma$ subunits containing a CWIL motif and the ability of non-prenylated types ( $\mathrm{B}$ and $\mathrm{C}$ ) to provide membrane localization for the $\mathrm{G} \beta \gamma$ dimer.

It has been reported that two of the Arabidopsis $\mathrm{G} \gamma$ subunits, AGG1 and AGG2, are prenylated in vivo $[27,28]$. Both proteins are type A subunits and contain conventional CaaX motifs, (CLIL and CSIL respectively), being rather exceptions to the type A consensus Ctermini (CWIL). On the other hand, since the first aliphatic amino acid is solvent exposed and is not involved in any hydrophobic interactions, as are the two terminal amino acids, its position in CaaX could in theory accommodate any amino acid [59]. This theoretical rule is supported by the high variability observed in this position in all eukaryotes (Table 1). In fact, a human Gy5 subunit with an artificially added CWIL C-terminal motif was prenylated in transfected cells, but proteolytic cleavage of the three terminal amino acids was suppressed [60].
Therefore it is possible that despite the presence of tryptophan in place of the first aliphatic residue in CaaX plant Gy subunits, they could still be prenylated. Interestingly, it has been recently established that Arabidopsis PGGT I exhibits more specificity for CaaX motifs containing leucine in the terminal position than PGGT I enzymes from metazoans and yeast [61]. We found that most type A subunits terminate in leucine (Figure 1B, Table 1). This may imply that type A Gy subunits are mostly modified with a geranylgeranyl moiety. The preferential prenylation of Arabidopsis AGG1 and AGG2 subunits by PGGT I has been experimentally demonstrated $[27,28]$. On the other hand, it was shown that Arabidopsis AGG2 that ends in CGCSIL is prenylated on the -4 cysteine (4th position from the end) while is also $\mathrm{S}$-acylated on the -6 cysteine, demonstrating a dual lipidation [27,28]. This feature, two cysteines separated by an amino acid, is conserved in type A sequences (Figure 1B, Table 1), suggesting that S-acylation of the -6 cysteine could be a common modification for plant $\mathrm{G} \gamma$ subunits. The presence of aromatic and basic amino acids has been confirmed to promote S-acylation of a nearby cysteine [62,63]. Therefore, the tryptophan present in the most common C-terminus of type $\mathrm{A}$ (CRCWIL) could serve as a facilitator of S-acylation of the -6 cysteine, assuming that it is not cleaved after prenylation of the second cysteine.

The plant $G \gamma$ subunits without prenylation motifs, namely type $B$ and half of type $C$ subunits, cannot be prenylated by PFT or PGGT I. Nevertheless, they can still be functional $\mathrm{G} \gamma$ subunits anchoring the $\mathrm{G} \beta \gamma$ dimer to the membrane. A prominent characteristic of all these sequences is an overrepresentation of positively charged amino acids (arginine, lysine) combined with aromatic residues (tryptophan, phenylalanine) and highly hydrophobic residues (isoleucine and leucine) at the $\mathrm{C}$ terminus. Such amino acid combination is also found at the $\mathrm{C}$-terminus of a number of membrane proteins and it has been established that these amino acids form an amphipathic $\alpha$-helix, able to anchor the proteins to the plasma membrane [64-68]. We therefore hypothesize that a similar structure could be formed at the Cterminus of plant $\mathrm{G} \gamma$ subunits providing affinity for the plasma membrane. A representative of type $B$, rice RGG2, was detected in the plasma membrane fraction, despite absence of a prenylation motif [26]. At the same time YFP-fused type B subunits from soybean were also detected on the plasma membrane [19]. Additionally, in the Arabidopsis mutant plp lacking the common PFT/ PGGT I $\alpha$-subunit and, hence, incapable of prenylation, AGG2 was shown to form stable membrane association, assumingly due to a polybasic C-terminal block [28]. No doubt, further experimental data is required to unequivocally establish the intracellular topology of the 
type B Gy subunits and post-translational modification patterns of plant $\mathrm{G}$ y subunits in general. Nevertheless, we would like to draw attention to the possibility that plant's unique C-terminal structure enables $\mathrm{Gy}$ subunits to target the plasma membrane regardless of the prenylation status, which would greatly distinguish them from their animal counterparts.

\section{A new nomenclature for plant $\mathrm{G} y$ subunits}

We believe that it will be very advantageous in the future to unequivocally identify the different $\mathrm{G} \gamma$ subunits as members of one of the three types defined in this report, since it could point to specific post-translational protein processing and possibly have important functional implications. For this reason we propose to use the type as an integral part of the Gy subunits' name for future studies. We realize the limits of our analysis and predict that new types of $\mathrm{G} \gamma$ subunits could be discovered in the future. For instance our preliminary studies revealed a new form (type?) of $\mathrm{G} \gamma$ related proteins in primitive land plants (Trusov, Botella unpublished data). Therefore, we emphasize that the new proposed nomenclature will easily accommodate newly discovered types, by using the sequential letter code (A, B, C, D, E and so on). It is also important to consider the common directions for plant nomenclature widely accepted by plant biologists to use the two first letters to represent a species name. In this way the three existing Arabidopsis Gy subunits could be referred as "AtGGA1", referring to Arabidopsis thaliana $\underline{\text { G-protein }}$ Gamma subunit type $\underline{\mathrm{A}}$, number 1 , (currently named "AGG1" [11]), "AtGGA 2 " (currently named "AGG2" [12]) and "AtGGC1" (currently named "AGG3"[10]). Similarly, for rice the nomenclature would apply as "OsGGA1" (currently named "RGG1" [26]), "OsGGB1" (currently named "RGG2" [26]), "OsGGC1" (currently named "GS3" [34]), "OsGGC2" (AACV01018633.1 ) and "OsGGC3" (currently named "DEP1" [35]).

\section{Conclusion}

We would like to make a short note to propose some caution on how to interpret past and future functional research into the Arabidopsis AtGGA1 and AtGGA2 subunits (previously AGG1 and AGG2). It is important to keep in mind that both subunits belong to type $A$ and that no type B subunit is present in Arabidopsis; therefore generalizations to other plants species are inherently risky. It is possible that AtGGA1 and AtGGA2 have evolved to take up some or all of the functions that type B subunits have in other species. It is thus important to study type A subunits in other species since they could have different or more restricted roles than those observed for AtGGA1 and AtGGA2. In addition, it is also important to establish the role of type B subunits, for which we still don't have any functional information.

\section{Methods}

\section{Database searches}

BLAST searches against the Genebank databases were run using full-length AGG1 (AF283673), AGG2 (AF347077), AGG3 (AAT85756), RGG1 (AB120662) and RGG2 (AP005647) protein sequences known to be plant Gy subunits. The soybean proteins [19] were published later than our original search was done. From the significant hits a subset of approximately 500 sequences was extracted, covering over 100 land plants species. The low score sequences were also considered and analyzed if conserved motifs (DPLL/I and CaaX" (asterisk represent the termination signal)) were identified. ESTs presenting parts of a putative gene were assembled by eye using SED.exe program from VOSTORG package [69]. Sequences containing identical or almost identical reading frames were considered redundant and reduced to one. Sequences containing full length or nearly full length reading frames were selected for further analysis.

\section{Phylogenetic analysis}

Protein sequence alignment was done using CLUSTALOMEGA [40]. The program is provided on EMBL-EBI web site http://www.ebi.ac.uk. Manual alignments were done using program SED.exe and analysis of inversions and repeats was done with dotmap.exe provided in package VOSTORG [69].

Phylogenetic analysis was performed using package PHYLIP 3.66 [41]. The package was used as described in manual provided with the programs. Namely, the seqboot.exe with default settings was used to generate file with 1000 bootstrapped data sets. 100 bootstraps were used for preliminary analyses to generate phylogenetic trees with the following algorithms: Protein/nucleotide Sequence Parsimony, Protein/nucleotide maximum likelihood, Neighbor-Joining, UPGMA, Fitch-Margoliash. All programs were used at default settings except for resetting for multiple data sets. 1000 bootstraps were generated for final parsimonious trees reconstructions. Package PhyML-aBayes [42,43] was also used to generate maximum likelihood tree using different substitution models for stationary amino-acid frequencies provided with the program.

Protein weblogos for Figure 1B were designed using Berkley University website http://weblogo.berkeley.edu/ logo.cgi [70].

Phylogenetic trees were visualized using program FigTree v1.3.1. http://tree.bio.ed.ac.uk/software/figtree/. 


\section{Availability of supporting data}

The additional data supporting the results of this article is available from authors by request.

\section{Additional file}

Additional file 1: Figure S1. Repetitive elements in Gossypium raimondii putative $\mathrm{G} \gamma$ type $\mathrm{C}$ subunit sequence. The elements are highlighted in yellow/green. Figure S2. Insertions/deletions in Gy type C gene. * indicates identical nucleotides. Figure S3. Projection of exon boundaries on protein sequence of $\mathrm{G} \gamma \mathrm{C}$ subunits from selected eukaryotic species; conserved DPLL motif highlighted in green; hyphen and amino acids highlighted in yellow display positions of exon boundaries. Table S1. Amino acid content (\%) and approximate length of the cysteine-rich domain of type C Gy subunits.

\section{Competing interests}

The authors declare that they have no competing interests.

\section{Authors' contributions}

YT collected data, conducted phylogenetic, structural and statistical analyses. DC was involved in data collection, interpretation of the results and has made substantial contributions to conception and design of the project. JB designed and coordinated the project. YT and JB wrote the manuscript. All the authors read and approved the final manuscript.

\section{Acknowledgements}

This work was supported by the Australian Research Council (Grant number DP1094152).

\section{Author details}

${ }^{1}$ Plant Genetic Engineering Laboratory, School of Agriculture and Food Sciences, University of Queensland, Brisbane, Queensland 4072, Australia. Biology Department, 208 Mueller Laboratory, Pennsylvania State University, University Park, Pennsylvania 16802, USA.

Received: 28 June 2012 Accepted: 15 October 2012

Published: 31 October 2012

\section{References}

1. Gautam N, Downes GB, Yan K, Kisselev O: The G-protein $\beta$ y complex. Cell Signal 1998, 10:447-455.

2. Gilman AG: G-proteins - transducers of receptor-generated signals. Annu Rev Biochem 1987, 56:615-649.

3. McIntire WE: Structural determinants involved in the formation and activation of $G$ protein $\beta \gamma$ dimers. Neurosignals 2009, 17:82-99.

4. Assmann SM: Plant G proteins, phytohormones, and plasticity: three questions and a speculation. Science's STKE 2004, 2004:20.

5. Perfus-Barbeoch L, Jones AM, Assmann SM: Plant heterotrimeric G protein function: insights from arabidopsis and rice mutants. Current Opinion in Plant Biology 2004, 7:719-731.

6. Trusov Y, Botella JR: New faces in plant innate immunity: heterotrimeric G proteins. J Plant Biochem Biotechnol 2012, in press.

7. Trusov Y, Jorda L, Molina A, Botella JR: $G$ proteins and plant innate immunity. Netherlands: Springer; 2010

8. Warpeha KM, Upadhyay S, Yeh J, Adamiak J, Hawkins SI, Lapik YR, Anderson MB, Kaufman LS: The GCR1, GPA1, PRN1, NF-Y signal chain mediates both blue light and abscisic acid responses in arabidopsis. Plant Physiol 2007, 143:1590-1600.

9. Assmann SM: Heterotrimeric and unconventional GTP binding proteins in plant cell signalling. Plant Cell 2002, 2002:S355-373. Supplement

10. Chakravorty D, Trusov Y, Zhang W, Sheahan MB, Acharya BW, McCurdy DW, Assmann SM, Botella JR: A highly atypical heterotrimeric $G$ protein $\gamma$ subunit is involved in guard cell $\mathrm{K}^{+}$channel regulation and morphological development in Arabidopsis thaliana. Plant J 2011, 67:840-851.

11. Mason MG, Botella JR: Completing the heterotrimer: isolation and characterization of an arabidopsis thaliana $\mathrm{G}$ protein $\gamma$-subunit CDNA. Proc Natl Acad Sci U S A 2000, 97:14784-14788.
12. Mason MG, Botella JR: Isolation of a novel G-protein $\gamma$-subunit from arabidopsis thaliana and its interaction with $\mathrm{G} \beta$. Biochim Biophys Acta 2001, 1520:147-153.

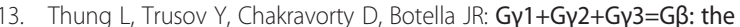
search for heterotrimeric G-protein $\gamma$ subunits in arabidopsis is over. J Plant Physiology 2012, 169:542-545.

14. Trusov Y, Rookes JE, Tilbrook K, Chakravorty D, Mason MG, Anderson D, Chen JG, Jones AM, Botella JR: Heterotrimeric G protein $\gamma$ subunits provide functional selectivity in $\mathrm{G} \beta \gamma$ dimer signaling in arabidopsis. Plant Cell 2007, 19:1235-1250.

15. Trusov Y, Zhang W, Assmann SM, Botella JR: GY1+Gy2 $\neq \mathrm{G} \beta$ : heterotrimeric $\mathrm{G}$ protein $\mathrm{G} \gamma$-deficient mutants do not recapitulate all phenotypes of Gß-deficient mutants. Plant Physiol 2008, 147:636-649.

16. Bisht NC, Jez JM, Pandey S: An elaborate heterotrimeric G-protein family from soybean expands the diversity of plant G-protein networks. New Phytol 2010, 190:35-48.

17. Hossain MS, Koba T, Harada K: Cloning and characterization of two full-length cDNAs, TaGA1 and TaGA2, encoding G-protein a subunits expressed differentially in wheat genome. Genes \& Genetic Systems 2003, 78:127-138.

18. Misra S, Wu Y, Venkataraman G, Sopory SK, Tuteja N: Heterotrimeric Gprotein complex and G-protein-coupled receptor from a legume (Pisum sativum): role in salinity and heat stress and cross-talk with phospholipase C. Plant J 2007, 51:656-669.

19. Choudhury SR, Bisht NC, Thompson R, Todorov O, Pandey S: Conventional and novel $\mathrm{G}$ p protein families constitute the heterotrimeric G-protein signaling network in soybean. PLoS One 2011, 6:e23361.

20. Lambright DG, Sondek J, Bohm A, Skiba NP, Hamm HE, Sigler PB: The 2.0 A crystal structure of a heterotrimeric G protein. Nature 1996, 379:311-319.

21. Sondek J, Bohm A, Lambright DG, Hamm HE, Sigler PB: Crystal structure of a G-protein By dimer at 2.1A resolution. Nature 1996, 379:369-374.

22. Marrari $Y$, Crouthamel M, Irannejad R, Wedegaertner PB: Assembly and trafficking of heterotrimeric G proteins. Biochemistry 2007, 46:7665-7677.

23. Anderson DJ, Botella JR: Expression analysis and subcellular localization of the Arabidopsis thaliana G-protein $\beta$-subunit AGB1. Plant Cell Reporter 2007, 26:1469-1480.

24. Balcueva EA, Wang Q, Hughes H, Kunsch C, Yu Z, Robishaw JD: Human G protein $\gamma_{11}$ and $\gamma_{14}$ subtypes define a new functional subclass. Experimental Cell Res 2000, 257:310-319.

25. Hurowitz EH, Melnyk JM, Chen YJ, Kouros-Mehr H, Simon MI, Shizuya H: Genomic characterization of the human heterotrimeric $G$ protein $\alpha, \beta$ and $\gamma$ subunit genes. DNA Res 2000, 7:111-120.

26. Kato C, Mizutani T, Tamaki H, Kumagai H, Kamiya T, Hirobe A, Fujisawa Y, Kato $H$, Iwasaki $Y$ : Characterisation of heterotrimeric $G$ protein complexs in rice plasma membrane. Plant J 2004, 38:320-331.

27. Adjobo-Hermans MJW, Goedhart J, Gadella TWJ Jr: Plant G protein heterotrimers require dual lipidation motifs of $\mathrm{Ga}$ and $\mathrm{G} y$ and do not dissociate upon activation. J Cell Sci 2006, 119:5087-5097.

28. Zeng Q, Wang X, Running MP: Dual lipid modification of Arabidopsis $\mathrm{G} \gamma$-subunits is required for efficient plasma membrane targeting. Plant Physiol 2007, 143:1119-1131.

29. Chakravorty D, Botella JR: Over-expression of a truncated Arabidopsis thaliana heterotrimeric $G$ protein $\gamma$ subunit results in a phenotype similar to $\alpha$ and $\beta$ subunit knockouts. Gene 2007, 393:163-170.

30. Iniguez-Lluhi JA, Simon MI, Robishaw JD, Gilman AG: G protein by subunits synthesized in Sf9 cells. Functional characterization and the significance of prenylation of y. J Biol Chem 1992, 267:23409-23417.

31. Simonds WF, Butrynski JE, Gautam N, Unson CG, Spiegel AM: G-protein $\beta \gamma$ dimers. Membrane targeting requires subunit coexpression and intact $\gamma$ C-A-A-X domain. J Biol Chem 1991, 266:5363-5366.

32. Takida S, Wedegaertner PB: Heterotrimer formation, together with isoprenylation, is required for plasma membrane targeting of $\mathrm{G} \beta \gamma$. J Biol Chem 2003, 278:17284-17290.

33. Altschul SF, Koonin EV: Iterated profile searches with PSI-BLAST-a tool for discovery in protein databases. Trends in Biochemical SCi 1998, 23:444-447.

34. Fan C, Xing Y, Mao H, Lu T, Han B, Xu C, Li X, Zhang Q: GS3, a major QTL for grain length and weight and minor QTL for grain width and thickness in rice, encodes a putative transmembrane protein. Theor Appl Genet 2006, 112:1164-1171. 
35. Huang X, Qian Q, Liu Z, Sun H, He S, Luo D, Xia G, Chu C, Li J, Fu X: Natural variation at the DEP1 locus enhances grain yield in rice. Nat Genet 2009 41:494-497

36. Takano-Kai $\mathrm{N}$, Jiang $\mathrm{H}$, Kubo $\mathrm{T}$, Sweeney M, Matsumoto T, Kanamori $\mathrm{H}$, Padhukasahasram B, Bustamante C, Yoshimura A, Doi K, McCouch S: Evolutionary history of GS3, a gene conferring grain length in rice. Genetics 2009, 182:1323-1334.

37. Botella JR: Can heterotrimeric $G$ proteins help to feed the world? Trends Plant Sci 2012, 17:563-568.

38. Cook LA, Schey KL, Cleator JH, Wilcox MD, Dingus J, Hildebrandt JD: Identification of a region in $\mathrm{G}$ protein $\gamma$ subunits conserved across species but hypervariable among subunit isoforms. Protein Sci 2001, 10:2548-2555.

39. Temple BRS, Jones AM: The plant heterotrimeric G-protein complex. Annual Rev Plant Biology 2007, 58:249-266.

40. Sievers F, Wilm A, Dineen D, Gibson TJ, Karplus K, Li W, Lopez R, McWilliam $H$, Remmert M, Soding J, et al: Fast, scalable generation of high-quality protein multiple sequence alignments using Clustal Omega. Mol Syst Biol 2011, 7:539.

41. Felsenstein J: PHYLIP - phylogeny inference package (version 3.2) Cladistics 1989, 5:164-166.

42. Guindon S, Dufayard JF, Lefort V, Anisimova M, Hordijk W, Gascuel O: New algorithms and methods to estimate maximum-likelihood phylogenies: assessing the performance of PhyML 3.0. Syst Biol 2010, 59:307-321.

43. Guindon S, Gascuel O: A simple, fast, and accurate algorithm to estimate large phylogenies by maximum likelihood. Syst Biol 2003, 52:696-704.

44. Finet C, Timme RE, Delwiche CF, Marletaz F: Multigene phylogeny of the green lineage reveals the origin and diversification of land plants. Curr Biol 2010, 20:2217-2222.

45. Jansen $G$, Thijssen $\mathrm{KL}$, Werner $\mathrm{P}$, van der Horst M, Hazendonk E, Plasterk RH: The complete family of genes encoding $\mathrm{G}$ proteins of caenorhabditis elegans. Nat Genet 1999, 21:414-419.

46. Krystofova S, Borkovich KA: The heterotrimeric G-protein subunits GNG-1 and GNB-1 form a Gßy dimer required for normal female fertility, asexual development, and galpha protein levels in Neurospora crassa. Eukaryotic Cell 2005, 4:365-378.

47. Zhang N, Long Y, Devreotes PN: GY in Dictyostelium: its role in localization of $\mathrm{G} \beta \gamma$ to the membrane is required for chemotaxis in shallow gradients. Mol Biology of the Cell 2001, 12:3204-3213.

48. Jones AM, Assmann SM: Plants: the latest model system for G-protein research. EMBO Rep 2004, 5:572-578.

49. Ullah H, Chen J-G, Temple B, Boyes DC, Alonso JM, Davis KR, Ecker JR, Jones AM: The $\beta$-Subunit of the Arabidopsis $G$ protein negatively regulates auxin-induced cell division and affects multiple developmental processes. Plant Cell 2003, 15:393-409.

50. Warpeha KM, Kaufman LS: Opposite ends of the spectrum: plant and animal g-protein signaling. Plant Signaling and Behavior 2007, 2:480-482.

51. Llorente F, Alonso-Blanco C, Sanchez-Rodriguez C, Jorda L, Molina A: ERECTA receptor-like kinase and heterotrimeric $\mathrm{G}$ protein from arabidopsis are required for resistance to the necrotrophic fungus plectosphaerella cucumerina. Plant J 2005, 43:165-180.

52. Suharsono U, Fujisawa $Y$, Kawasaki T, Iwasaki $Y$, Satoh H, Shimamoto K: The heterotrimeric $\mathrm{G}$ protein a subunit acts upstream of the small GTPase Rac in disease resistance of rice. Proc Natl Acad Sci U S A 2002, 99:13307-13312.

53. Trusov Y, Rookes JE, Chakravorty D, Armour D, Schenk PM, Botella JR: Heterotrimeric G-proteins facilitate arabidopsis resistance to necrotrophic pathogens and are involved in jasmonate signaling. Plant Physiol 2006, 140:210-220.

54. Trusov Y, Sewelam N, Rookes JE, Kunkel M, Nowak E, Schenk PM, Botella JR: Heterotrimeric $G$ proteins-mediated resistance to necrotrophic pathogens includes mechanisms independent of salicylic acid-, jasmonic acid/ethylene- and abscisic acid-mediated defense signaling. Plant $J$ 2009, 58:69-81.

55. Zhang W, He SY, Assmann SM: The plant innate immunity response in stomatal guard cells invokes G-protein-dependent ion channel regulation. Plant J 2008, 56:984-996.

56. Delgado-Cerezo M, Sanchez-Rodriguez C, Escudero V, Miedes E, Fernandez PV, Jorda L, Hernandez-Blanco C, Sanchez-Vallet A, Bednarek P, SchulzeLefert $P$, et al: Arabidopsis heterotrimeric G-protein regulates cell wall defense and resistance to necrotrophic fungi. Mol Plant 2012, 5:98-114.
57. Crowell DN, Huizinga DH: Protein isoprenylation: the fat of the matter. Trends Plant Sci 2009, 14:163-170.

58. Maurer-Stroh S, Washietl S, Eisenhaber F: Protein prenyltransferases. Genome Biol 2003, 4:212

59. Lane KT, Beese LS: Thematic review series: lipid posttranslational modifications. Structural biology of protein farnesyltransferase and geranylgeranyltransferase type I. J Lipid Res 2006, 47:681-699.

60. Kilpatrick EL, Hildebrandt JD: Sequence dependence and differential expression of $\mathrm{G} \gamma 5$ subunit isoforms of the heterotrimeric $\mathrm{G}$ proteins variably processed after prenylation in mammalian cells. J Biol Chem 2007, 282:14038-14047.

61. Andrews M, Huizinga DH, Crowell DN: The CaaX specificities of Arabidopsis protein prenyltransferases explain era1 and $g g b$ phenotypes. BMC Plant Biology 2010, 10:118

62. Bizzozero OA, Bixler HA, Pastuszyn A: Structural determinants influencing the reaction of cysteine-containing peptides with palmitoyl-coenzyme $A$ and other thioesters. Biochim Biophys Acta 2001, 1545:278-288.

63. Hemsley PA: Protein S-acylation in plants. Mol Membr Biol 2009, 26:114-125

64. Gambhir A, Hangyas-Mihalyne G, Zaitseva I, Cafiso DS, Wang J, Murray D, Pentyala SN, Smith SO, McLaughlin S: Electrostatic sequestration of PIP2 on phospholipid membranes by basic/aromatic regions of proteins. Biophys J 2004, 86:2188-2207.

65. Prinz WA, Hinshaw JE: Membrane-bending proteins. Crit Rev Biochem Mol Biol 2009, 44:278-291.

66. Zhang W, Crocker E, McLaughlin S, Smith SO: Binding of peptides with basic and aromatic residues to bilayer membranes: phenylalanine in the myristoylated alanine-rich $C$ kinase substrate effector domain penetrates into the hydrophobic core of the bilayer. J Biol Chem 2003, 278:21459-21466.

67. Roy MO, Leventis R, Silvius JR: Mutational and biochemical analysis of plasma membrane targeting mediated by the farnesylated, polybasic carboxy terminus of K-ras4B. Biochemistry 2000, 39:8298-8307.

68. Yeung T, Terebiznik M, Yu L, Silvius J, Abidi WM, Philips M, Levine T, Kapus A, Grinstein S: Receptor activation alters inner surface potential during phagocytosis. Science 2006, 313:347-351.

69. Zharkikh AA, Rzhetsky A, Morosov PS, Sitnikova TL, Krushkal JS: VOSTORG: a package of microcomputer programs for sequence analysis and construction of phylogenetic trees. Gene 1991, 101:251-254.

70. Crooks GE, Hon G, Chandonia JM, Brenner SE: WebLogo: a sequence logo generator. Genome Res 2004, 14:1188-1190.

\section{doi:10.1186/1756-0500-5-608}

Cite this article as: Trusov et al:: Diversity of heterotrimeric G-protein $\gamma$ subunits in plants. BMC Research Notes 2012 5:608

\section{Submit your next manuscript to BioMed Central and take full advantage of:}

- Convenient online submission

- Thorough peer review

- No space constraints or color figure charges

- Immediate publication on acceptance

- Inclusion in PubMed, CAS, Scopus and Google Scholar

- Research which is freely available for redistribution 